\title{
Role of Antibiotics in Orofacial Antibioma and its Management: A Case Report
}

\author{
Pilavuthil Rilna ${ }^{1}$, Ramanujam Sathyanarayanan ${ }^{2}$, Thamizhp Pozhil Guna ${ }^{3}$, Nithin Joseph ${ }^{4}$, Kumaravel Raghu ${ }^{5}$
}

\begin{abstract}
Antibiotics are used for therapeutic and prophylactic purposes. In the case of odontogenic infections, these drugs are commonly used as supportive measure for controlling the spread of infection. Proper understanding of the disease process, mode of action of antibiotics, and monitoring the susceptibility of the microbes to the particular drugs are very essential for a successful treatment outcome. As there is no clear guideline for the use of antibiotics in dentistry, it has been misused or overused in most of the cases. This leads to drug resistance and various other complications. Antibioma is a tough walled abscess which forms commonly as the squeal of inadequate pus drainage during infection and inappropriate use of antibiotics by the patient. Here we present a case of antibioma which was formed due to persistent odontogenic infection. Nonsurgical management was done using magnesium sulfate dressing which was changed regularly. Complete reduction of the antibioma was noticed at follow-up period.
\end{abstract}

Keywords: Antibioma, Antibiotics, Odontogenic infection, Resistance. Journal of Scientific Dentistry (2019): 10.5005/jp-journals-10083-0901

\section{INTRODUCTION}

Antibiotics are used for treating various odontogenic infections in the oral cavity. Most of the times the dental clinicians prescribe the drugs without the awareness and the knowledge of susceptibility of the microbes to the particular antibiotics. The prescription of antibiotics in dental clinics has increased from 6.7 to $11.3 \%$ in recent years. ${ }^{1}$ Also the frequent and prolonged use of the antibiotics by the patients will lead to antibiotic resistance, ${ }^{2,3}$ easy availability of the counter selfmedication drugs adds to the development of resistant strains. ${ }^{4-6}$ Failure of proper control of the infection will cause various local and systemic complications. If proper drainage of pus is not established and treated only by antibiotics, pus localizes and forms a tough fibrous swelling known as antibioma. It is characterized by localized swelling which is painless, smooth, non-tender, and firm on palpation. The established treatment for antibioma is to surgically incise and drain it like an abscess under analgesics and sometimes antibiotics. Here we present a case of antibioma which results due to inadequate pus drainage along with inappropriate use of antibiotics. The patient was treated conservatively by local application of mix of magnesium sulfate and glycerin. Regular follow-up of the patient showed a significant result on antibioma.

\section{Case Description}

A 53-year-old male patient reported to the Department of Oral and Maxillofacial Surgery with the chief complaint of swelling in the right lower third of the face for 1 month. Patient had the history of pain in the right lower back tooth region 1 month back, for which he consulted a private practitioner who extracted the offending tooth followed by antibiotic coverage (cap. amoxicillin $500 \mathrm{mg}$ twice a day and tab. metronidazole $400 \mathrm{mg}$ thrice a day and tab. diclofenac $(50 \mathrm{mg})+$ paracetamol $(500 \mathrm{mg})$ for 5 days thrice a day). After 5 days, patient noticed that the swelling did not reduce, and he continued taking antibiotic on and off for
${ }^{1-5}$ Department of Oral and Maxillofacial Surgery, Indira Gandhi Institute of Dental Sciences, Sri Balaji Vidyapeeth (a Deemed University), Pillayarkuppam, Puducherry, India

Corresponding Author: Pilavuthil Rilna, Department of Oral and Maxillofacial Surgery, Indira Gandhi Institute of Dental Sciences, Sri Balaji Vidyapeeth (a Deemed University), Pillayarkuppam, Puducherry, India, Phone: +91 9629419016, e-mail: rilnaajith@gmail.com

How to cite this article: Rilna P, Sathyanarayanan R, Guna TP, Joseph $\mathrm{N}$, Raghu K. Role of Antibiotics in Orofacial Antibioma and its Management: A Case Report. J Sci Dent 2019;9(1):13-14.

Source of support: Nil

Conflict of interest: None

the swelling for next two weeks, even after which the swelling was persistent. On examination, a diffuse swelling measuring around $4 \mathrm{~cm} \times 3 \mathrm{~cm}$ was present at the right lower third of face extending $2 \mathrm{~cm}$ posteriorly from the right corner of the mouth, $2 \mathrm{~cm}$ below the ala tragus line and $1 \mathrm{~cm}$ superiorly from the lower border of the mandible. The skin over the swelling appears normal (Fig. 1). On palpation swelling was non-tender, movable and firm in consistency. Intraorally no abnormalities detected. Orthopantomograph does not reveal any abnormalities and showed a clean socket of extracted 47. Based on history and clinical findings it was provisionally diagnosed as antibioma. Conservative management of the swelling was planned. Dressing over the antibioma was done using the mix of magnesium sulfate and glycerin. The dressing was changed regularly and follow-up shows significant reduction in the size of antibioma (Fig. 2).

\section{Discussion}

Antibioma is a chronic sterile, tough fibrous abscess formed commonly due to prolonged and inappropriate use of antibiotics for infections. In the present case report, patient underwent extraction of offended tooth to eradicate the infection, however inadequate 


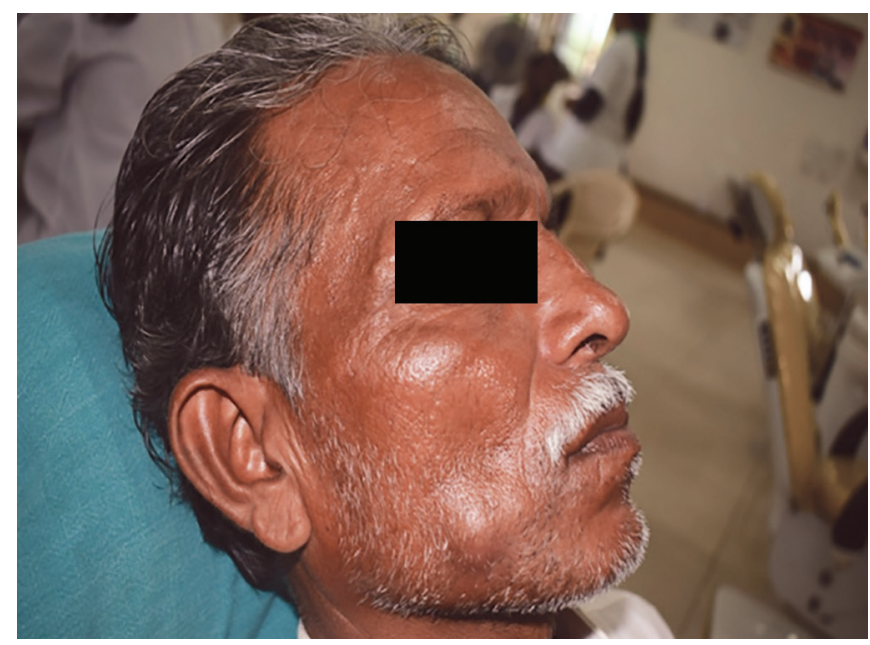

Fig. 1: Clinical images showing the extraoral location of the antibioma

drainage of the abscess and lack of proper postoperative follow-up leads to persistence of residual infection.

Inappropriate use of antibiotics involves systemic side effects such as gastric, neurological disorders hematological and dermatological. The most significant side effect is the development of resistance to antimicrobial drugs. To minimize such side effects, and to ensure maximum efficacy, proper rationale for use of antibiotic should be considered. Although antibiotics have cured many diseases while benefiting a huge number of individuals, a sharp rise in the number of drug resistant strains of bacteria have occurred in parallel due to their inappropriate use.

In the case of odontogenic infections, there were no proper guidelines regarding the use of antibiotics to treat them. Natural and semisynthetic penicillin (amoxicillin) is considered to be the first drug of choice by some clinicians ${ }^{7}$ while others favor the usage of combination drugs, because of the increasing number of bacterial strains resistant to beta lactams, as well as due to the pharmacological advantages of using a broad spectrum drug and its tolerance. ${ }^{8}$ Antibiotics should be considered as an adjunct to appropriate management of odontogenic infections. ${ }^{9}$ For example, in case of the poor drainage of pus or the sealing of residual microorganisms, the patient may not obtain significant benefits from antibiotic treatment, leading to further complications such as antibioma. It represents the persistent of infection and sometimes huge swellings will cause pain and other discomforts for the patients.

There are various management options for antibioma but the most widely accepted method was the incision and drainage of the swelling and the evacuation of the pus. ${ }^{10}$ On the contrary, in our treatment approach it was decided to use a nonsurgical method to resolve the existing antibioma. Regular dressing over the swelling was done using magnesium sulfate (Epsom salt) and glycerin. Rationale behind using magnesium sulfate was that it works by drawing the infected pus to the surface of the skin before rupturing and leaking out, thereby reduces the swelling. In the present case complete reduction of the pus and proper eradication of the infection was noted in the follow-up periods.

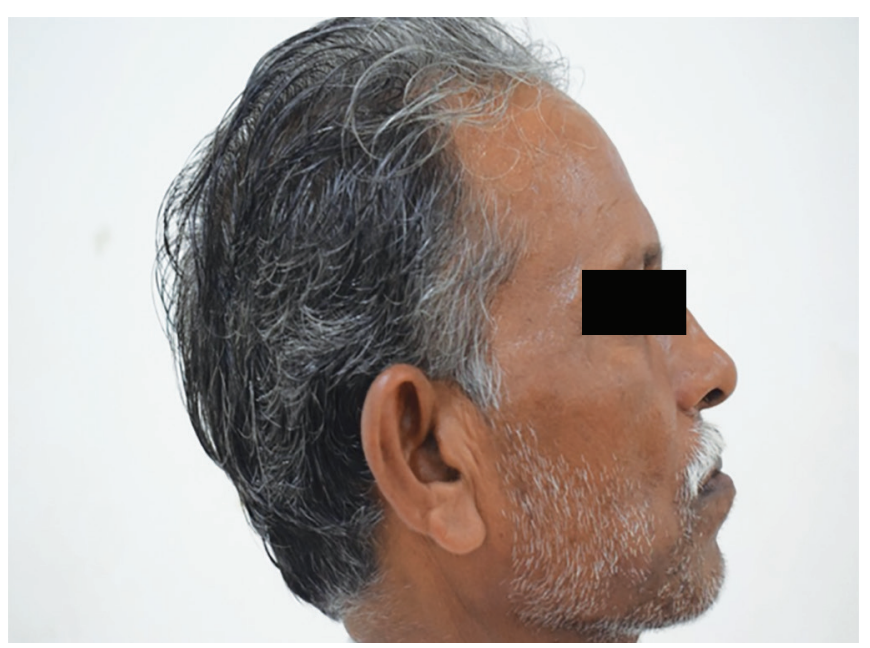

Fig. 2: Extraoral clinical view after the management

\section{Conclusion}

Public awareness programmers and educating health care professional can be promising in controlling the inappropriate use of antibiotics for infections, thereby avoiding unwanted effects related to it. Appropriate treatment protocol should be followed in case of management of odontogenic infections and antibiotics coverage should always be taken under proper guidelines.

\section{References}

1. Marra F, George D, Chong M, Sutherland S, Patrick DM. Antibiotic prescribing by dentists has increased: why? J Am Dent Assoc 2016;147(5):320-327. DOI: 10.1016/j.adaj.2015.12.014.

2. Dar-Odeh NS, Abu-Hammed OA, Al-Omiri MK, Khraisat AS, Shehabi AA. Antibiotic prescribing practices by dentists: a review. Ther Clin Risk Manag 2010;6:301-306. DOI: 10.2147/TCRM.S9736.

3. Poveda Roda R, Bagan JV, Sanchis Bielsa JM, Carbonell Pastor E. Antibiotic use in dental practice. A review. Med Oral Patol Oral Cir Bucal 2007;12(3):E186-E192.

4. Cope AL, Wood F, Francis NA, Chestnutt IG. General dental practitioners' perceptions of antimicrobial use and resistance: a qualitative interview study. Br Dent J 2014;217(5):E9. DOI: 10.1038/sj.bdj.2014.761.

5. Muzaffar D, Mahdey HM, Sonjaya D, Zafar MS. Tendency of selfmedication among various malaysian ethnicities. $\mathrm{Br} J$ Pharmacol 2016;9(2):1-7. DOI: 10.9734/BJPR/2016/21826.

6. Afolabi AO, Akinmoladun VI, Adebose IJ, Elekwachi G. Self-medication profile of dental patients in Ondo State, Nigeria. Niger J Med 2010;19(1):96-103. DOI: 10.4314/njm.v19i1.52488.

7. Kuriyama T, Nakagawa K, Karasawa T, Saiki Y, Yamamoto E, Nakamura S. Past administration of beta-lactam antibiotics and increase in the emergence of beta-lactamase-producing bacteria in patients with orofacial odontogenic infections. Oral Surg Oral Med Oral Pathol Oral Radiol Endod 2000;89(2):186-192. DOI: 10.1067/moe.2000.102040.

8. Kirkwood KL. Update on antibiotics used to treat orofacial infections. Alpha Omegan 2003;96(4):28-34.

9. Harneet S, Ambika G, Aarti S, Samidha K. Non surgical treatment of antibioma in oro-facial region. Int J Curr Res 2017;9(8):56666-56667.

10. Patil N, Kaul D, Tambuwala A, Pingal C, Sheikh MS, Pendharkar S. Large antibioma resulting from injudicious use of antibiotics: a case report. Int J Dent Med Res 2015;1(5):89-92. 